\title{
Immunoelectron Microscopic Detection of Band 3 Protein during Erythroid Cell Differentiation by a Monoclonal Antibody
}

\author{
Yoshito Sadahira $^{1}$, Yuko Hirao ${ }^{1}$, Kenzou Uehira ${ }^{2}$, and Tetsuo Kimoto ${ }^{1}$ \\ ${ }^{I}$ Department of Experimental Pathology and 'Electron Microscope Center, Kawasaki Medical School, \\ Matsushima 577, Kurashiki 701-01, Japan
}

Key words: Immunocytochemistry/monoclonal antibody/erythroblasts/band 3 protein/mice

\begin{abstract}
$A B S T R A C T$. We created a monoclonal antibody, designated EB1 (IgM, kappa), that reacts with erythroblasts by fusion of P3-X63-Ag8.653 with splenocytes of rats immunized with erythroblastic islands isolated from mice spleens. Western blotting revealed that EB1 reacted with the band 3 protein of the erythrocytic membrane. It stained erythrocytes and erythroblasts, forming clusters in the bone marrow, splenic red pulp, and fetal liver, but did not stain other tissues in the cryostat sections. The EB1 antigen was detected during dimethyl sulfoxide-induced differentiation of murine erythroleukemia cells. Immunoelectron microscopy revealed that the EB1 antigen was expressed from the basophilic erythroblasts during normal erythroid differentiation. Preferential segregation of the EB1 antigen on the cell membrane of the nucleating erythroblasts was not observed. These results suggest that $\mathrm{EB} 1$ is specific for erythrocyte band 3 protein and may be useful for studying erythroid cell differentiation.
\end{abstract}

Band 3 protein is a major integral protein of the erythrocytes. It is linked to the cytoskeleton through ankyrin and functions as an anion transporter (9). The expression of the band 3 protein during erythroid cell differentiation has been extensively studied in mice, rats, humans, and chickens $(1,2,4,10,16,17,21,23)$. The studies indicate that the protein is expressed during the differentiation of erythropoietin-responsive cells to erythrocytes. However, most of the studies have been done using transformed erythroid cells and polyclonal antibodies. Few studies have been performed to detect the band 3 on the normal erythroblasts.

We have established a monoclonal antibody that reacts with mouse erythrocyte band 3 protein by immunizing rats with erythroblastic islands isolated from the anemic mouse spleen. Here we report the specificity of the antibody and immunoelectron microscopic detection of the antigen on normal erythroblasts from the anemic mice.

\section{MATERIALS AND METHODS}

Isolation of erythroblastic islands (EI). EI were isolated from spleens of bled mice using collagenase digestion, unit gravity sedimentation, and Percoll density gradient centrifuga-

Abbreviations used: $\mathrm{ABC}$, avidin-biotin-peroxidase complex; DMSO, dimethylsulfoxide; EI, erythroblastic islands; $\mathrm{mAb}$, monoclonal antibody; MEL, murine erythroleukemia. tion as previously described (19). Briefly, 10- to 16-week-old $\mathrm{C} 3 \mathrm{H} / \mathrm{HeN}$ mice (Charles River Japan, Inc., Tokyo) were bled by heparinized capillary tubes from the retro-orbital sinus 4 days $(0.4 \mathrm{ml})$ and 1 day $(0.25 \mathrm{ml})$ before being sacrificed. After the mice were killed by cervical dislocation, their spleens were excised, washed in Eagle's minimum essential medium (MEM) (GIBCO, Grand Island, NY), and minced in the medium using scissors. The fragments of 2 spleens were incubated in $15 \mathrm{ml} 0.075 \%$ type 4 collagenase from Clostridium histolyticum (Sigma, St Louis, Mo) and 0.004\% deoxyribonuclease 1 (DNase) (Sigma) in MEM for $30 \mathrm{~min}$ in a $37^{\circ} \mathrm{C}$ water bath with constant shaking. After passing the suspension through a syringe with an 18 gauge needle several times, a small amount of undigested white tissue was discarded. The suspension was washed and re-suspended in $7 \mathrm{ml} \mathrm{MEM} \mathrm{con-}$ taining $0.004 \%$ DNase. This suspension was gently layered on $35 \mathrm{ml}$ MEM containing 30\% horse serum (GIBCO) in a $50 \mathrm{ml}$ plastic tube. Forty-five minutes later, aggregates sedimented on the bottom were collected, suspended in $20 \mathrm{ml} \mathrm{MEM} \mathrm{con-}$ taining 50\% Percoll (prior adjusted to $300 \mathrm{mOs} / \mathrm{kg}$, Pharmacia Fine Chemicals, Uppsala, Sweden), and gently layered on $10 \mathrm{ml}$ of $100 \%$ Percoll in a glass centrifuge tube. The column was spun at an average of $400 \mathrm{~g}$ for $20 \mathrm{~min}$. Red aggregates (EI fraction) enriched between the 50\% Percoll column (density: $1.064 \mathrm{~g} / \mathrm{ml}$ ) and the $100 \%$ Percoll column (density: 1.122 $\mathrm{g} / \mathrm{ml}$ ) were harvested by Pasteur pipette, suspended in MEM, and washed by centrifugation at $100 \mathrm{~g}$ for $5 \mathrm{~min}$. This enriched EI fraction, containing 90.1\% erythroblasts and 3.4\% macrophages, was used for immunization and immunoelec- 
tron microscopic study.

Production of a monoclonal antibody against erythroblasts. Eight-week-old Wistar rats (Clea Japan, Inc., Tokyo) were pre-immunized with EI $\left(4.0 \times 10^{7}\right.$ total nucleated cells) in complete Freund's adjuvant. Two weeks later the animals were immunized intraperitoneally with EI. Four weeks later the rats were boosted with EI. Three days after the boosting, spleen cells were fused with $\mathrm{P} 3-\mathrm{X} 63-\mathrm{Ag} 8.653$ mouse myeloma cells (supplied by the Institute of Physical and Chemical Research, Tsukuba) by a published procedure (13). Hybrid clones were selected in hypoxanthine-aminopterin-thymidine (HAT) medium (Sigma). Of the 125 hybrids, one showed exclusive reactivity with erythroblasts of EI on cytocentrifuge preparation as determined by immunoperoxidase staining. The selected hybridoma, designated EB1, was cloned by submitting it to limiting dilution 2 times, and was then transplanted to athymic mice (Balb/c nu-nu AJcl, Clea Japan, Inc.) that had been treated with pristane (Sigma). After a period of 14 to 18 days, ascitic fluid was collected and precipitated with $50 \%$ ammonium sulfate. The precipitate was dialysed using phosphate-buffered saline (PBS) and used for immunostaining.

Monoclonal antibody isotype determination. The immunoglobulin isotype of the mAb was determined by a ZYMED MonoAb-ID/SP rat kit (Zymed Laboratories, Inc., San Francisco, CA).

Immunoperoxidase staining. The tissues from $\mathrm{C} 3 \mathrm{H} / \mathrm{HeN}$ or 8-week-old C57BL/6N mice (Clea Japan) treated with or without phlebotomy were examined using frozen and paraffin-embedded tissues. For cryostat-sections, the excised tissues were embedded in Tissue Tek OCT compound (Miles, Naperville, IL), and were snap-frozen in $n$-hexan cooled at $-80^{\circ} \mathrm{C}$. Acetone-fixed $6 \mu \mathrm{m}$ sections were stained with monoclonal antibody (mAb) using the indirect method. Briefly, after treatment with $10 \%$ normal goat serum, the sections were stained with the $\mathrm{mAb}$ for $90 \mathrm{~min}$ at room temperature. They were then washed in PBS and incubated for $45 \mathrm{~min}$ in peroxidase-conjugated goat anti-rat IgG (KPL, Inc., Maryland) which had been affinity purified and absorbed by mouse serum. After washing in PBS, the sections were stained for peroxidase activity with $0.3 \mathrm{mg} / \mathrm{ml} \mathrm{3,3-diaminobenzidin}$ tetrahydrocloride and $0.005 \%$ hydrogen peroxide in tris buffer. For paraffin-sections, the tissues were fixed with Carnoy's solution, dehydrated, and embedded in paraffin. Four $\mu \mathrm{m}$ sections were treated with $0.3 \%$ hydrogen peroxide to eliminate endogenous peroxidase activity prior to staining with the mAb using avidin-biotin-peroxidase complex (ABC) method as previously described (18). Cytocentrifuge preparations of isolated EI were stained with EB1 mAb as previously described (18).

Immunoelectron microscopy. The EI were fixed with 0.1 M phosphate buffer containing $4 \%$ paraformaldehyde and $0.5 \%$ glutaraldehyde for $30 \mathrm{~min}$ at room temperature. They were washed in PBS and treated with $0.001 \%$ hydrogen peroxide for $10 \mathrm{~min}$. After washing in PBS containing $0.1 \%$ Tri- ton $\mathrm{X}-100$, they were incubated in normal goat serum for $3 \mathrm{hr}$ at room temperature and then incubated in $\mathrm{EB} 1 \mathrm{mAb}$ overnight at $4^{\circ} \mathrm{C}$. After washing in PBS containing $0.1 \%$ Triton $\mathrm{X}-100$, they were incubated in peroxidase-conjugated anti-rat IgG for $3 \mathrm{hr}$ at room temperature. They were then washed in PBS containing $0.1 \%$ Triton X-100 and re-fixed with $1 \%$ glutaraldehyde for $30 \mathrm{~min}$. Subsequently, they were washed again in PBS and stained for peroxidase activity. After the immunochemical reaction, EI were postfixed with $1 \%$ osmium tetroxide, dehydrated, and embedded in Epon. Ultrathin sections were stained with uranyl acetate and then examined by electronmicroscope.

Cell lines. The murine erythroleukemia cell line, B8/3 (15), was provided as a gift by Dr. M. Obinata, Department of Cell Biology, The Research Institute for Tuberculosis and Cancer, Tohoku University, Sendai, Japan. The cells were maintained in RPMI-1640 medium supplemented with $10 \%$ FBS and $100 \mu \mathrm{g} / \mathrm{ml}$ kanamycin. For induction of differentiation, DMSO (Sigma) was added to the culture at a final concentration of $1.5 \%$. The extent of differentiation was determined using the diaminobenzidin reaction to sort out hemoglobin-containing cells. EB1 antigen expression was also determined by immunostaining of cytocentrifuge preparations of the cells cultured in DMSO. The macrophages cell lines (P388D1 and J774A. 1) and myelomonocytic cell lines (M1-T22 and WEHI-3) were obtained from the Japanese Cancer Research Resources Bank, Tokyo.

Western blotting for surface membrane proteins. Erythrocytes were isolated from drawn mouse blood by centrifugation. Ghosts were obtained by the method of Fairbanks et al. (3) and were stocked at a protein concentration of $3 \mathrm{mg} / \mathrm{ml}$ at $-80^{\circ} \mathrm{C}$. For SDS-PAGE, ghosts were mixed with a $4 \times$ gel sample buffer and analyzed according to the method of Laemmli (11), gels contained $7.5 \%$ polyacrylamide. After electrophoresis, the gels were soaked for $20 \mathrm{~min}$ in a transfer buffer ( $2.5 \mathrm{mM}$ sodium phosphate, $\mathrm{pH} 6.7$ ), and electrophoretically transferred to an Immunodyne immunoaffinity membrane (Pall Ultrafine Filtration Corp., Tokyo) (14). The membranes were then incubated in skim milk at $4^{\circ} \mathrm{C}$ overnight and incubated in the $\mathrm{mAb}$ for $2 \mathrm{~h}$ at room temperature. After washing in PBS containing $0.1 \%$ Triton $\mathrm{X}$, they were incubated in biotinylated anti-rat IgG (Vector) for $1 \mathrm{hr}$ at room temperature. They were subsequently washed, incubated in $\mathrm{ABC}$ for $45 \mathrm{~min}$, and washed. They were then stained for peroxidase activity with $0.3 \mathrm{mg} / \mathrm{mL}$ 3,3-diaminobenzidine tetrahydrochloride and $0.005 \%$ hydrogen peroxide in tris buffer.

\section{RESULTS}

Immunohistochemical reactivity of the monoclonal antibody (EB1) with tissues. EB1 was IgM, kappa type immunogloblin. In cytocentrifuge preparation of erythroblastic islands isolated from bled mouse spleen, EB1 stained most cells surrounding central macrophages. In cryostat sections, EB1 stained erythrocytes 
and hematopoietic clusters in splenic red pulp, bone marrow (Fig. 1A), and fetal liver. As shown in Table I, the $\mathrm{mAb}$ did not stain cells other than erythrocytic cells in the various tissues so far examined, including kidney
(Fig. 1B). After phlebotomy in adult mice, the hematopoietic cells positive for EB1 antigen were markedly increased in number and formed large colonies in the splenic red pulp (Fig. 1C, D). Interestingly, the anti-

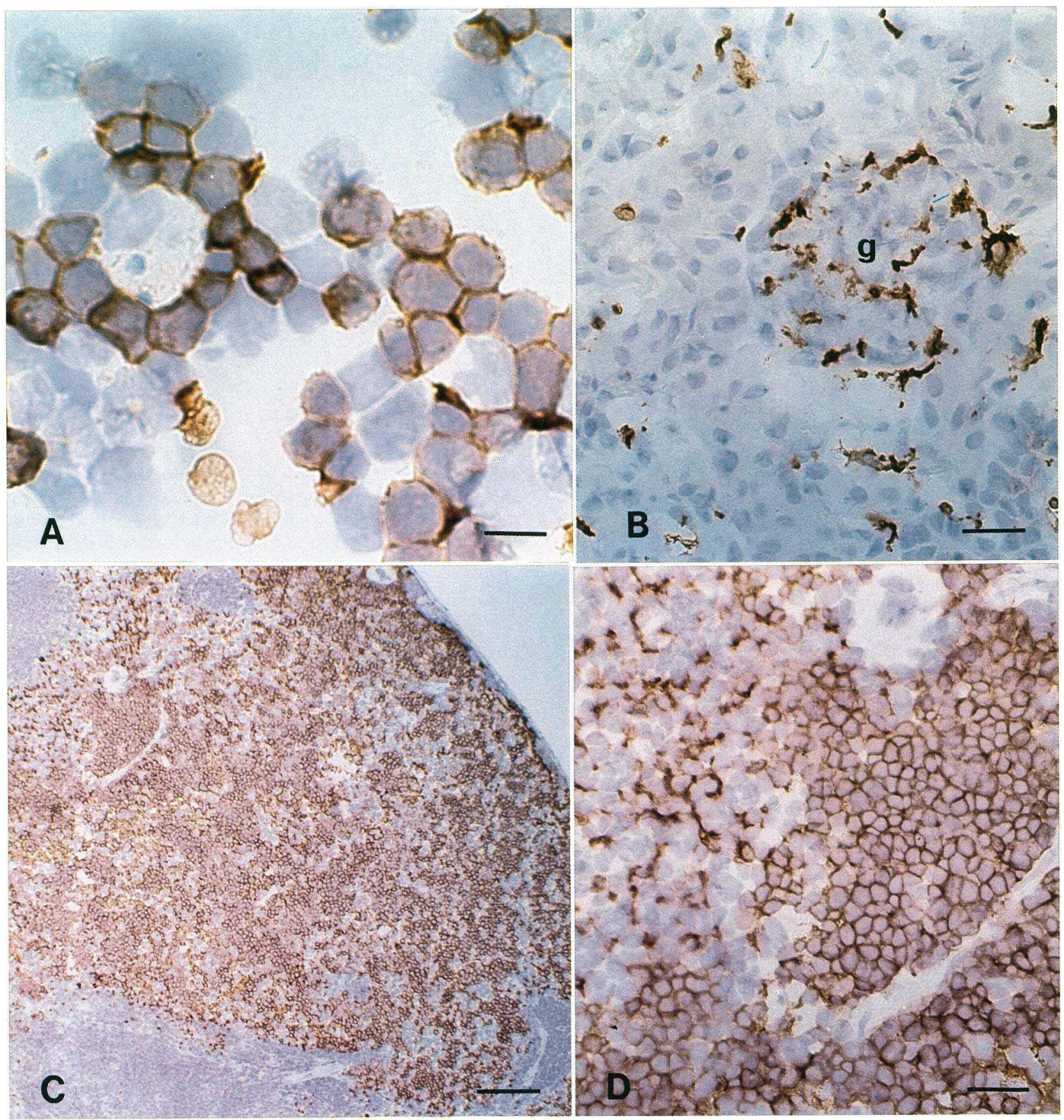

Fig. 1. Immunoperoxidase staining of $\mathrm{C} 3 \mathrm{H} / \mathrm{He}$ mouse tissues. Bar, $10 \mu \mathrm{m}$ (A); $25 \mu \mathrm{m}$ (B, D); $100 \mu \mathrm{m}(\mathrm{C})$.

(A) EB1 staining in cytocentrifuge preparation of the bone marrow. Erythroid cells were stained. (B) EB1 staining in cryostat section of kidney. Reaction products were localized in erythrocytes. g, a glomerius. (C) EB1 staining in cryostat section of anemic mouse spleen. EB1 positive hematopoietic cells occupied red pulp. (D) Higher magnification of C. EB1 positive erythroblasts forming compact colonies are seen. Erythrocytes in the marginal zone are stained in scattered form and are easily distinguished from erythroblasts. 
Table I. Reactivity of EB1 with mouse tissues.*

\begin{tabular}{lc}
\hline \multicolumn{1}{c}{ Tissue } & Reactivity \\
\hline Brain & $(-)$ \\
Heart & $(-)$ \\
Lung & $(-)$ \\
Stomach & $(-)$ \\
Intestine & $(-)$ \\
Liver, Adult & $(-)$ \\
$\quad$ Fetal & $(+)$ \\
Kidney & $(-)$ \\
Urinary Bladder & $(-)$ \\
Ovary & $(-)$ \\
Salivary Gland & $(-)$ \\
Adrenal Gland & $(-)$ \\
Skeletal Muscle & $(-)$ \\
Skin & $(-)$ \\
Thymus & $(-)$ \\
Mesenteric Lymph Node & $(-)$ \\
Bone Marrow & $(+)$ \\
Spleen, red pulp & $(+)$
\end{tabular}

* Reactivity was examined by immunoperoxidase staining in tissue sections.

body was reactive also in paraffin-embedded sections. Hematopoietic foci were more clearly identified in the cryostat section than in the paraffin sections, in the cryostat section, the hematopoietic cells stained were round and the erythrocytes were sickle shaped.

Immunocytochemical reactivity of EBI with cell lines. We studied EB1 antigen expression in mouse cell lines. EB1 reacted with murine erythroleukemia cells only after treatment with $1.5 \%$ dimethyl sulfoxide (DMSO) (Table II).

Antigen recognized by EB1. Western blotting revealed that EB1 reacts with an erythrocyte membrane protein (a single band at $\sim 100$ kilodalton) presumably corresponding to the band 3 protein revealed by Coomassie brilliant blue staining of SDS polyacrylamide gels (Fig. 2).

Table II. Reactivity of EB1 with VARIOUs Cells.

\begin{tabular}{lc}
\hline \multicolumn{1}{c}{ Cells } & Reactivity \\
\hline M1-T22 cells & $(-)$ \\
WEHI-3 cells & $(-)$ \\
P388-D1 cells & $(-)$ \\
J774A.1 cells & $(-)$ \\
MEL (B8/3) cells & \\
DMSO $^{-}$ & $(-)$ \\
DMSO $^{+}$ & $(+)$ \\
\hline
\end{tabular}

Reactivity was examined by immunoperoxidase staining in cytocentrifuge preparations.

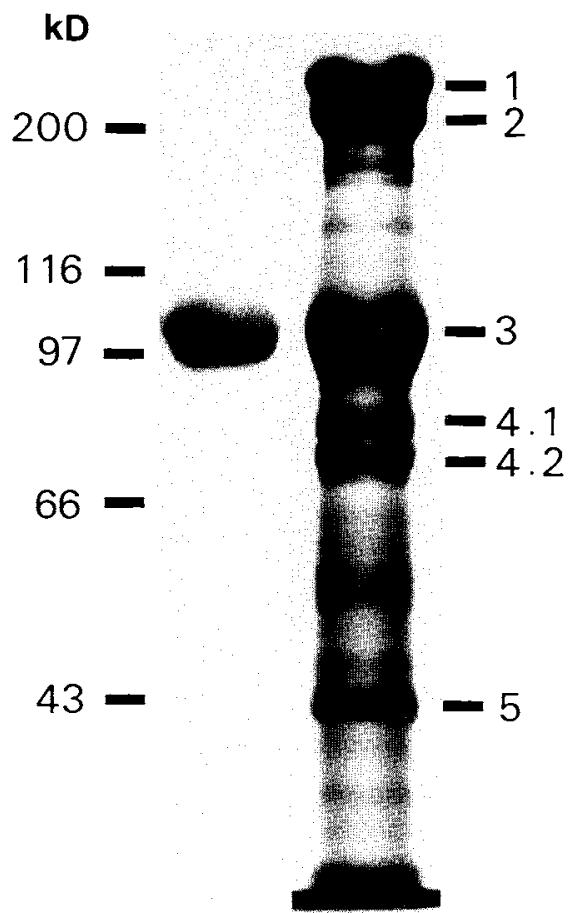

Fig. 2. SDS-PAGE analysis of the erythrocytic membrane using EB1. The erythrocyte ghosts were subjected to SDS-PAGE (right lane) and Western blotting (left lane). EB1 stains 95 to 105 kilodalton (kD) protein corresponding to band 3 protein detected by Coomassie blue staining of the gel (right lane). Band 1 and 2, spectrin. Band 5, actin.

EBI expression during normal erythroid differentiation. Immunoperoxidase electron microscopy of the erythroid-rich fraction isolated from anemic mouse spleen revealed that EB1 stained only the plasma membranes of the erythroid cells. Other types of hematopoietic cells, including granulocytes, lymphocytes, and megakaryocytes were not stained. We divided erythroid cells into three types by the staining intensity with EB1, EB1-negative cells, faintly EB1-positive cells, and strongly EB1-positive cells (Table III, Fig. 3A). The EB1-negative cells were larger than the EB1-positive

Table III. RELATIONSHIP BETWEEN MORPHOLOGY AND EB1 EXPRESSION DURING ERYTHROID CELL DIFFERENTIATION.

\begin{tabular}{lcl}
\hline $\begin{array}{c}\text { Staining } \\
\text { Intensity }\end{array}$ & $\begin{array}{c}\text { Cell size }(\mu \mathrm{m})^{*} \\
\text { Mean } \pm \mathrm{SD}, \mathrm{n}=10)\end{array}$ & Morphology \\
\hline or \pm & $8.5 \pm 0.2$ & $\begin{array}{c}\text { Proerythroblasts and basophilic } \\
\text { erythroblasts }\end{array}$ \\
+ & $7.6 \pm 0.7$ & $\begin{array}{c}\text { Basophilic erythroblasts } \\
\text { Polychromatic and orthochro- } \\
+\end{array}$ \\
& $6.3 \pm 1.0$ & matic erythroblasts \\
\hline
\end{tabular}

\footnotetext{
* Cell size was examined by measuring diameter of cells in the immunoelectron micrographs.
} 

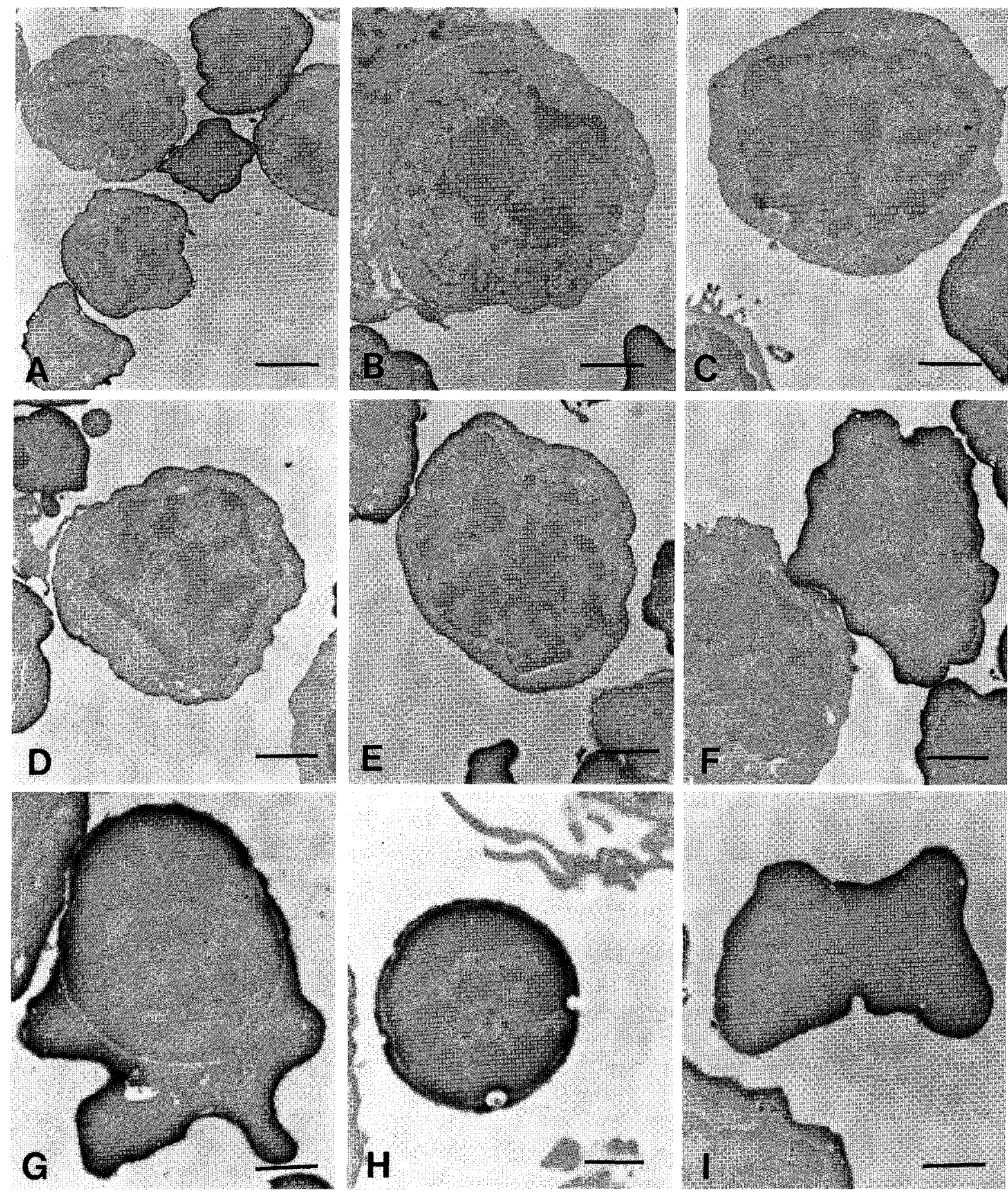

Fig. 3. Immunoelectron microscopic detection of EB1 on mouse erythroblasts isolated from anemic mouse spleen. Bar, 3.1 $\mu \mathrm{m}$ (A); $1.9 \mu \mathrm{m}$ (B, C, D, E, F); $1.0 \mu \mathrm{m}(\mathrm{G}, \mathrm{H}, \mathrm{I})$.

(A) an EB1-negative cell, faintly EB1-positive cells, and strongly EB1-positive cells are seen. (B) an EB1-negative proerythroblast attached to a central macrophage. (C) an EB1-negative basophilic erythroblast. (D) a faintly EB1-positive basophilic erythroblast. (E) a faintly EB1-positive basophilic erythroblast. (F) a strongly EB1-positive polychromatic erythroblast. (G) a strongly EB1-positive orthochromatic erythroblast. (H) a strongly EBI-positive extruded nucleus. (I) a strongly EB1-positive reticulocyte. 
cells. Most of the former had many mitochondria and irregular shaped nuclei with prominent nucleoli. The morphology of the cells took on the ultrastructural characteristics of proerythroblasts or early basophilic erythroblasts (Fig. 3B, C). On the other hand, the faintly EB1-positive cells had nuclei with more condensed chromatin. The nucleoli of the cells were less conspicuous or not seen (Fig. 3D, E). They corresponded to basophilic erythroblasts. The strongly EB1-positive cells were polychromatic erythroblasts (Fig. 3F) and orthochromatic erythroblasts (Fig. 3G). EB1 strongly stained the plasma membrane which enclosed the extruded nucleus (Fig. $3 \mathrm{H}$ ) as well as reticulocytes (Fig. 3I).

\section{DISCUSSION}

In the present study using immunoelectron microscopy with a newly established $\mathrm{mAb}$, we clearly showed that the expression of band 3 protein begins at the basophilic erythroblasts during normal erythroid differentiation. The intensity of the staining increases from basophilic erythroblasts to more mature cells, suggesting continuous synthesis and accumulation of the protein.

It has been reported that the polyclonal antibody to purified erythrocyte band 3 protein stains kidney, sweat glands, lymphocytes, platelets, adult liver cells, gastric parietal cells, and embryonic kidney cells $(6,7,8)$. In addition, a $\mathrm{mAb}$ was reported that recognized both the human erythrocyte band 3 protein and the kidney band 3 -like protein (22). Recent studies using a band $3 \mathrm{cDNA}$ probe have revealed that band 3-related proteins exist in various tissues, including the stomach and the heart (11). Therefore, the fact that EB1 mAb used in this study stained only erythroid cells indicates that this $\mathrm{mAb}$ is clearly superior to polyclonal antibodies in specifically detecting the erythroid-specific band 3 protein.

The EB1 did not stain the living erythrocytic cells. It did not lyse them in the presence of complement (data not shown). In order to perform successful immunostaining, it was necessary to treat the fixed-cells with detergents such as Triton $\mathrm{X}-100$, suggesting that the antigenic site of EB1 is in the cytoplasmic domain of the band 3 protein.

During the enucleation of the normal erythroblasts, immunofluorescence microscopy showed that glycophorin and spectrin were segregated preferentially on the surface of reticulocytes but not on the membrane enclosing extruded nuclei $(5,20)$. Patel and Lodish reported that band 3 protein remained with the cytoplasmic fragment of enucleating murine erythroleukemia (MEL) cells (16). However, our results from immunoperoxidase electron microscopy with EB1 suggest that band 3 protein is not segregated preferentially in the enucleating erythroblasts isolated from the anemic mouse spleen. This discrepancy might be related to the difference in the cells used in the experiments. In fact, it is known that MEL cells do not show complete enucleation in contrast to normal erythroblasts (16).

It is fairly difficult to clearly distinguish erythroblasts from other types of hematopoietic cells in routinely stained tissue-sections. Although this new mAb reacts with both erythrocytes and erythroblasts, the different staining pattern between erythroblasts and erythrocytes in the tissue-sections allowed us to distinguish erythropoietic foci in hematopoietic tissues. In addition, this $\mathrm{mAb}$ stains erythroid cells not only in cryostat sections but also in paraffin-embedded sections, which suggests that this membrane marker can be applied to routinely processed sections.

In conclusion, the EB1 could be a useful $\mathrm{mAb}$ for studying erythroid cell differentiation in vivo and in vitro.

Acknowledgments. This work was supported by a Grant-in-Aid (No. 0177026) for Scientific Research from the Ministry of Education, Science and Culture of Japan and a grant (No. 1-509) from Kawasaki Medical School.

\section{REFERENCES}

1. Chang, H., Langer, P., and Lodish, H.F. (1976). Asynchronous synthesis of erythrocyte membrane proteins. Proc. Natl. Acad. Sci. USA, 73: 3206-3210.

2. Cox, J.V., Moon, R.T., and Lazarides, E. (1985). Anion transporter: highly cell-type-specific expression of distinct polypeptides and transcripts in erythroid and nonerythroid cells. $J$. Cell Biol., 100: 1548-1557.

3. Fairbanks, G., Steck, T.L., and Wallach, D.F.H. (1971). Electrophoretic analysis of the major polypeptides of the human erythrocyte membrane. Biochemistry, 10: 2606-2617.

4. Fukuda, M., Fukuda, M.N., Papayannopoulou, T., and HAKOMORI, S. (1980). Membrane differentiation in human erythroid cells: Unique profiles of cell surface glycoproteins expressed in erythroblasts in vitro from three ontogenic stages. Proc. Natl. Acad. Sci. USA, 77: 3474-3478.

5. GEIDUSCHEK, J.B. and SINGER, S.J. (1979). Molecular changes in the membrane of mouse erythroid cells accompanying differentiation. Cell, 16: 149-163.

6. Hazen-Martin, D.J., Pasternack, G., Spicer, S.S., and SENS, D.A. (1986). Immunolocalization of band 3 protein in normal and cystic fibrosis skin. J. Histochem. Cytochem., 34: 823-826.

7. Kay, M.M.B., Tracey, C.M., Goodman, J.R., Cone, J.C., and BASSEL, P.S. (1983). Polypeptides immunologically related to band 3 are present in nucleated somatic cells. Proc. Natl. Acad. Sci. USA, 80: 6882-6886.

8. Kellokumpu, S., Neff, L., Jamsa-Kellokumpu, S., Kopito, R., and BARON, R. (1988). A 115-kD polypeptide immunologically related to erythrocyte band 3 is present in Golgi membranes. Science, 242: 1308-1311.

9. KopITO, R.R. and LODISH, H.F. (1985). Structure of the murine anion exchange protein. J. Cell Biochem., 29: 1-17.

10. Koury, M.J., Bondurant, M.C., and Mueller, T.J. (1986). The role of erythropoietin in the production of principal erythrocyte proteins other than hemoglobin during terminal 
erythroid differentiation. J. Cell Physiol., 126: 259-265.

11. Kudrycki, K.E., Newman, P.R., and Shull, G.E. (1990). cDNA cloning and tissue distribution of mRNA as for two proteins that are related to the Band $3 \mathrm{Cl}-/ \mathrm{HCO} 3-$ exchanger. $J$. Biol. Chem., 265: 462-471.

12. LAEMMLI, U.K. (1970). Cleavage of structural protein during the assembly of the head of bacteriophage T4. Nature, 227: 680-685.

13. McKearn, T.J., Smilek, D.E., and Fitch, F.W. (1980). Ratmouse hybridoma and their application to studies of the major histocompatibility complex. In Monoclonal Antibodies. (R.H. Kennett, T.J. Mckearn, and K.B. Bechtol, eds.). New York, Plenum Press, p 219.

14. Marlow, S.J. and Handa, A.K. (1987). Immuno slot-blot assay using a membrane which covalently binds protein. $J$. Immunol. Methods, 101: 133-139.

15. Ostertag, W., Melderis, H., Steinheider, G., Kluge, N., and DuBE, S. (1972). Synthesis of mouse hemoglobin and globin mRNA in leukaemic cell cultures. Nature New Biol., 239: 231-234.

16. PATEL, V.P. and Lodish, H.F. (1987). A fibronectin matrix is required for differentiation of murine erythroleukemia cells into reticulocytes. J. Cell Biol., 105: 3105-3118.

17. Sabban, E.L., Sabatini, D., Marchesi, V.T., and Adesnik, M. (1980). Biosynthesis of erythrocyte membrane protein band 3 in DMSO-induced Friend erythroleukemia cells. J. Cell Physiol., 104: 261-268.

18. Sadahira, Y., Mori, M., Awai, M., Watarai, S., and YASUdA, T. (1988). Forssman glycosphingolipid as an immunohistochemical marker for mouse stromal macrophages in hematopoietic foci. Blood, 72: 42-48.

19. SAdahira, Y., Mori, M., and Kimoto, T. (1990). Isolation and short-term culture of mouse splenic erythroblastic islands. Cell Struct. Funct., 15: 59-65.

20. SARris, A.H. and Palade, G.E. (1982). Immunofluorescent detection of erythrocyte sialoglycoprotein antigen on murine erythroid cells. J. Cell Biol., 93: 591-603.

21. TONG, B.D. and Goldwasser, E. (1981). The formation of erythrocyte membrane proteins during erythropoietin-induced differentiation. J. Biol. Chem., 256: 12666-12672.

22. Wagner, S., Vogel, R., LietzKe, R., КоOв, R., and DRENCKHAHN, D. (1987). Immunochemical characterization of a band 3-like anion exchanger in collecting duct of human kidney. Am. J. Physiol, 253: F213-221.

23. Woods, C.M., Boyer, B., Vogt, P.K., and Lazarides, E. (1986). Control of erythroid differentiation: A synchronous expression of the anion transporter and the peripheral components of the membrane skeleton in AEV- and S13-transformed cells. J. Cell Biol., 103: 1789-1798.

(Received for publication, December 6, 1990 and in revised form, January 21,1991 ) 